\title{
Commonalities and specificities between attention deficit/ hyperactivity disorder and autism-spectrum disorders: can epidemiology contribute?
}

\author{
Maria Melchior $^{1} \cdot$ Laura Pryor $^{1} \cdot$ Judith van der Waerden $^{1}$
}

Published online: 24 July 2015

(C) Springer-Verlag Berlin Heidelberg 2015

\section{Introduction}

Attention deficit/hyperactivity disorder (ADHD) and autism spectrum disorders (ASD) are among the most frequent neurodevelopmental disorders in children and adolescents (5.9-7.1\% prevalence for ADHD [28] and approximately $0.62-0.70 \%$ for ASD [17]). Core symptoms as well as treatment differ between these two disorders, yet some characteristics are shared, including symptoms of inattention, social dysfunction, and difficult behavior (e.g. tantrums, aggression) [2]. What is more, these two multifactorial disorders frequently co-occur [6] and have several risk factors in common (e.g. male sex, low birth weight, in utero neurotoxic exposures, low family socioeconomic position) $[7,8]$. This raises questions regarding (1) the specificity of underlying etiological factors, (2) the degree of functional impairment across different profiles of comorbidity and (3) optimal treatment-particularly for children who have both ADHD and ASD [6]. Epidemiology can help gain a better understanding of the origins and consequences of ADHD and ASD, and several articles in this month's issue of European Child and Adolescent Psychiatry provide a brilliant illustration.

Maria Melchior

maria.melchior@inserm.fr

1 INSERM, Institut Pierre Louis d'Epidémiologie et de Santé Publique (IPLESP UMRS 1136), Sorbonne Universités, UPMC Univ Paris 06, 75012 Paris, France

\section{What is in a case definition?}

The first step in searching the causes of a disorder is to provide a definition of the phenomenon under study. This may seem obvious, yet different forms of measurement have different properties and entail strengths and limitations which are not always acknowledged. Data on children's mental health problems come either from clinical records or from specifically designed studies. The use of clinical records offers the advantage of providing a diagnosis established by a health professional knowledgeable of the disorder. Yet while this is the best approach when assessing an individual, its validity at a population level is not always guaranteed. As shown by the study conducted by Ashwood et al. [3] in 66 clinical centres in 31 countries in Europe, tools used to systematically ascertain ASD vary across countries with specific differences between Western and Eastern Europe. This complicates the comparisons of studies examining risk factors of ASD in different settings and makes it difficult to merge different datasets to study ASD in large samples. This leads the authors to call for greater scientific collaboration to enable "the translation, adaptation and validation of ASD diagnostic tools in multiple languages and cultures as well as evaluation of existing free/open access measures to determine their screening and diagnostic accuracy in different communities' [3].

Another issue regarding the use of clinical records is that, as pointed out by Lehti et al. [15], they are by definition only available among individuals who have accessed the health care system. This is an unlikely source of major bias when studying severe mental health problems, but may be a concern in less severe disorders. In a study of over 7000 youths living in Finland, Lehti et al. find no association between youths' migrant background and their likelihood of Asperger syndrome diagnosis, which goes against 
research showing that children of immigrants have higher levels of autism than native children [16]. One possible explanation of this unexpected finding is that children of immigrant parents are less likely to be referred to mental health services in case of Asperger syndrome than those of non-immigrant parents, and therefore less likely to count as cases. The degree to which migrant status as well as other socio-demographic characteristics can influence individuals' access to services can vary according to the characteristics of the health care system, and Lehti et al.'s surprising finding calls for additional research on the links between migrant status and ASD in different settings.

An alternative to the use of clinical records is the implementation of studies which examine the presence of mental health symptoms in children in a systematic way-either through diagnostic schedules [e.g. Kiddie-Schedule for Affective Disorders and Schizophrenia (K-SADS) [27] or the Autism Diagnostic Interview (ADI) [3]] or through the scales which have been validated against clinical diagnosis [e.g. Child Behavioral Checklist (CBCL) [1] or the Strengths and Difficulties Questionnaire (SDQ) [9]]. In a study of over 4500 children recruited in 6 European countries, Kovess et al. [14] use the SDQ to examine a controversial research question-is maternal prenatal smoking a risk factor of ADHD? Combining parent and teacher reports, a more valid approach than single-informant reports, the authors find evidence of an association even after controlling for multiple covariates (adjusted OR 1.45). This is an important contribution to an area marked by widely divergent findings: while several studies set in community samples have found independent effects of maternal prenatal smoking on children's symptoms of ADHD-in an era when many women smoked during pregnancy [12] or controlling for multiple risk factors of behavioral problems $[19,29]$, studies conducted among siblings [23] or among children born to genetically unrelated mothers [24] have reported no association. However, study designs based on siblings or on children born using Assisted Reproductive Technologies may be limited by selection bias which makes participants different from the general population and could explain why findings differ from those of community samples [13]. Cross-country comparisons such as the one published by Kovess et al. are an elegant way of comparing settings in which levels of maternal smoking as well as ADHD rates differ. This study contributes to the ongoing debate about the long-term consequences of in utero exposure to nicotine on children's behavior [25]. Interestingly, studies examining the association between maternal prenatal smoking and ASD have generally reported no association [18], but given secular changes in diagnostic criteria of ASD and increased case recognition with time, this topic that requires additional research.

\section{The future of diagnosis in child and adolescent psychiatry?}

A recently proposed and promising approach to identify mental health problems in children and adolescents is the combination of 'observable behavior and neurobiological measurements' [27]. Although this mostly refers to genetic or neuroimaging marks-such as those identified by Sarkar et al. in relation to conduct disorder [22], other biological signs may also be relevant. In a study conducted among 53 adolescents with ADHD or ADHD + ASD, Bink et al. [5] report differences in electroencephalogram (EEG) power spectra between these two groups on different experimental tasks. Specifically, youths with ADHD had higher levels of theta activity than those with ADHD + ASD in the eyes open task, suggesting that while both groups show symptoms of inattention, their causes may be different-underarousal in adolescents with ADHD and abnormal neural connectivity in ADHD + ASD. The authors suggest that this pathophysiological difference may explain why youths with ADHD + ASD show worse treatment outcomes than those with ADHD alone, which is an interesting hypothesis to verify in future studies.

\section{Beyond case definition: the importance of non-clinical characteristics}

An important consideration in interpreting biological differences between groups is that adolescents who have both ADHD and ASD have the highest levels of risk factorsenvironmental and genetic - and the most severe forms of impairment, which are not entirely addressed by the use of stimulant medication. Several studies in the current issue of ECAP highlight the importance of characteristics which are not among core disorder symptoms with regard to youths' prognosis. Hagberg et al. [11] show that among youths with ASD, cognitive symptoms are an important predictor of comorbid ADHD as well as later executive function which is related to social, academic and occupational outcomes. Becker et al. [4] report that youths who have ADHD are disproportionately likely to experience later externalizing problems (specifically oppositional defiant disorder) or depressive symptoms if they have sleep problems (approximately $5 \%$ of variance explained). This is consistent with research showing that sleep problems predict later psychopathology in non-clinical samples $[10,26]$ and could be explained by the negative consequences of poor sleep on youths' self-control and emotional regulation. Finally, Roy et al. [21] highlight the importance of difficulties in interactions with others among youths with ADHD. This study based on 728 youths participating in the longitudinal Dutch 
TRAILS sample presents the strength of having collected data on peer relations from participants' classmates. The results show that ADHD, peer dislike and victimization independently predict later depression, particularly among girls. Overall, these studies point to the importance of nonclinical characteristics of neurodevelopmental disorders with regard to children's long-term outcomes, and call for multidisciplinary interventions involving health professionals but also other players including school teachers-as discussed in an innovative study conducted by Pereira et al. [20]—in efforts promoting children's mental health.

\section{Conclusion}

Attention deficit/hyperactivity disorder (ADHD) and autism spectrum disorders (ADS) tend to be frequent, yet because of insufficient detection, many cases may go unnoticed and untreated, particularly among children growing up in underprivileged settings. While rapid technological advances make it possible to envision the use of biological markers to refine diagnoses (and perhaps 1 day adapt treatment?), equally important is the understanding of nonclinical characteristics of youths who have these disorders, the environments in which they grow up, and the ways in which these can shape their risk of later psychopathology as well as social outcomes. To date, little is known about long-term trajectories of ADHD and ASD from childhood onwards and about factors that predict them, and the articles published in this issue of ECAP point to some important domains which will be exciting topics for future research in this area.

\section{References}

1. Achenbach TM (2007) Achenbach system of empirically-based assessment. http://www.aseba.org/

2. American Psychiatric Association (2013) Diagnostic and statistical manual of mental disorders, 5th edn. American Psychiatric Association, Arlington

3. Ashwood KL, Buitelaar J, Murphy D, Spooren W, Charman T (2015) European clinical network: autism spectrum disorder assessments and patient characterisation. Eur Child Adolesc Psychiatry (in Press)

4. Becker SP, Langberg JM, Evans SW (2015) Sleep problems predict comorbid externalizing behaviors and depression in young adolescents with attention-deficit/hyperactivity disorder. Eur Child Adolesc Psychiatry (in Press)

5. Bink M, van Boxtel GJ, Popma A, Bongers IL, Denissen AJ, van NC (2015) EEG theta and beta power spectra in adolescents with ADHD versus adolescents with ASD + ADHD. Eur Child Adolesc Psychiatry (in Press)

6. Cooper M, Martin J, Langley K, Hamshere M, Thapar A (2014) Autistic traits in children with ADHD index clinical and cognitive problems. Eur Child Adolesc Psychiatry 23:23-34
7. Fakhoury M (2015) Autistic spectrum disorders: a review of clinical features, theories and diagnosis. Int J Dev Neurosci 43:70-77

8. Galéra C, Cote SM, Bouvard MP, Pingault JB, Melchior M, Michel G, Boivin M, Tremblay RE (2011) Early risk factors for hyperactivity-impulsivity and inattention trajectories from age 17 months to 8 years. Arch Gen Psychiatry 68:1267-1275

9. Goodman R (1997) The strengths and difficulties questionnaire: a research note. J Child Psychol Psychiatry 38:581-586

10. Greene G, Gregory AM, Fone D, White J (2015) Childhood sleeping difficulties and depression in adulthood: the 1970 British Cohort Study. J Sleep Res 24:19-23

11. Hagberg B, Billstedt E, Nyden A, Gillberg C (2015) Asperger syndrome and nonverbal learning difficulties in adult males: selfand parent-reported autism, attention and executive problems. Eur Child Adolesc Psychiatry (in Press)

12. Keyes KM, Davey Smith G, Susser E (2014) Associations of prenatal maternal smoking with offspring hyperactivity: causal or confounded? Psychol Med 44(4):857-867. doi:10.1017/ S0033291713000986

13. Keyes KM, Smith GD, Susser E (2014) Commentary: smoking in pregnancy and offspring health: early insights into family-based and 'negative control' studies? Int J Epidemiol 43:1381-1388

14. Kovess V, Keyes KM, Hamilton A, Pez O, Bitfoi A, Koc C, Goelitz D, Kuijpers R, Lesinskiene S, Mihova Z, Otten R, Fermanian C, Pilowsky DJ, Susser E (2015) Maternal smoking and offspring inattention and hyperactivity: results from a cross-national European survey. Eur Child Adolesc Psychiatry (in Press)

15. Lehti V, Cheslack-Postava K, Gissler M, Hinkka-Yli-Salomaki S, Brown AS, Sourander A (2015) Parental migration and Asperger's syndrome. Eur Child Adolesc Psychiatry (in Press)

16. Lehti V, Hinkka-Yli-Salomaki S, Cheslack-Postava K, Gissler M, Brown AS, Sourander A (2013) The risk of childhood autism among second-generation migrants in Finland: a case-control study. BMC Pediatrics 13:171

17. Levy SE, Mandell DS, Schultz RT (2009) Autism. Lancet 374:1627-1638

18. Lyall K, Schmidt RJ, Hertz-Picciotto I (2014) Maternal lifestyle and environmental risk factors for autism spectrum disorders. Int J Epidemiol 43:443-464

19. Melchior M, Hersi R, van der Waerden J, Larroque B, SaurelCubizolles MJ, Chollet A, Galera C (2015) Maternal tobacco smoking in pregnancy and children's socio-emotional development at age 5: the EDEN mother-child birth cohort study. Eur Psychiatry 30:562-568

20. Pereira CA, Wen CL, Miguel EC, Polanczyk GV (2015) A randomised controlled trial of a web-based educational program in child mental health for schoolteachers. Eur Child Adolesc Psychiatry (in Press)

21. Roy A, Hartman CA, Veenstra R, Oldehinkel AJ (2015) Peer dislike and victimisation in pathways from ADHD symptoms to depression. Eur Child Adolesc Psychiatry (in Press)

22. Sarkar S, Daly E, Feng Y, Ecker C, Craig MC, Harding D, Deeley Q, Murphy DG (2015) Reduced cortical surface area in adolescents with conduct disorder. Eur Child Adolesc Psychiatry (in Press)

23. Skoglund C, Chen Q, D’Onofrio BM, Lichtenstein P, Larsson $\mathrm{H}$ (2014) Familial confounding of the association between maternal smoking during pregnancy and ADHD in offspring. J Child Psychol Psychiatry 55:61-68

24. Thapar A, Rice F, Hay D, Boivin J, Langley K, van den Bree M, Rutter M, Harold G (2009) Prenatal smoking might not cause attention-deficit/hyperactivity disorder: evidence from a novel design. Biol Psychiatry 66:722-727 
25. Tiesler CM, Heinrich J (2014) Prenatal nicotine exposure and child behavioural problems. Eur Child Adolesc Psychiatry 23:913-929

26. Touchette E, Chollet A, Galéra C, Fombonne E, Falissard B, Boivin M, Melchior M (2012) Prior sleep problems predict internalising problems later in life. J Affect Disord 143:166-171

27. Weissman MM (2011) Standardized interviews for diagnostic assessments of children and adolescents in psychiatric research. J Am Acad Child Adolesc Psychiatry 50:633-635
28. Willcutt EG (2012) The prevalence of DSM-IV attention-deficit/ hyperactivity disorder: a meta-analytic review. Neurotherapeutics 9:490-499

29. Zhu JL, Olsen J, Liew Z, Li J, Niclasen J, Obel C (2014) Parental smoking during pregnancy and ADHD in children: the Danish national birth cohort. Pediatrics 134:e382-e388 